\title{
Electrical and Dielectric Properties of Stitched Non-woven Engineered Fabrics Containing Activated Carbon Fiber
}

\author{
M. A. Saad ${ }^{1}$, M. F. Nasr ${ }^{1}$, and H. A. Yassen² and G. M. Turky ${ }^{3}$ \\ ${ }^{1}$ National Research Centre, Textile Research Division, Dokki, Giza, P.O.B. 12622, Egypt. \\ ${ }^{2}$ Faculty of Education, Helwan University, Cairo, Egypt. \\ ${ }^{3}$ Microwave Physics and Dielectrics Dept., Physics Research Division, National \\ Research Center, Giza, Egypt.
}

\begin{abstract}
MART TEXTILE is considered to be a new trend that can revolutionize the functionality

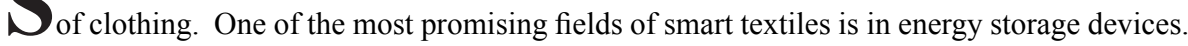
Recently, many research efforts focus on supercapacitor as an energy storage device that can overlap the gap between conventional batteries and traditional capacitors. Activated carbon fiber (ACF) is one of the important candidates for this application. Different groups of non-woven polyester fabrics were prepared with and without adding the activated carbons. The effect of structure of the samples on the permittivity, dielectric loss as well as the ac-conductivity is investigated and interpreted. The mechanism of the storage of the charge carriers is given by two different capacities. The first one is the capacity of the electric double layer at the interface between the electrode and the dielectric material. The second is the capacity due to the redox or what is called pseudo capacity. In this work, the broadband dielectric spectrometer, BDS, is employed to study the effect of frequency in the range of $1 \mathrm{mHz}-10 \mathrm{MHz}$ and sometimes temperature $\left(20-60{ }^{\circ} \mathrm{C}\right)$. The non-woven samples prepared with ACF showed the best results among the prepared nonwoven samples without activated carbon fibers and even nonwoven samples with carbon granules. This is due to the good electrical conductivity of activated carbon fiber used in the nonwoven samples.
\end{abstract}

\section{Introduction}

Nonwoven fabric is a fabric-like material made from staple short fiber and long fibers (continuous long), bonded together by chemical, mechanical, heat or solvent treatment. The term is used in the textile manufacturing industry to denote fabrics, such as felt, which are neither woven nor knitted [1].

The different types of nonwovens are classified into different kinds. The first classification is according to the method of production which is wet bonded, dry bonded, and spun bonded. The second is according to the technology of raw materials to give staple fiber nonwoven and filament fiber nonwoven. Itcan also be classified according to the end use of material into durable and semi-durable and to their properties to give flame retardant, water repellent and water absorbent nonwoven.
Nonwoven fabric bonding by means of spraying the binders is produced into or onto the textile structure by means of sprayers arranged above the moving web. The binder is saturated on the surface layers and does not penetrate far in the structure, which is normally quite thick [2].

Advantages of adhesive bonding are an exact measure of the amount of binders applied, uniform binder distribution and a soft fabric handle. In this work, activated carbon fiber and medium size activated carbon granules were mixed with the binders during the spraying process and later covered by another layer of no-nonwoven fabric of the same kind. Schematic diagram of the method of production and the shape of produced fabric are shown in Fig. 1 \& 2.

Activated carbon fibers (ACF) are porous carbon materials produced from a variety of fibrous carbonaceous precursors such as polyacrylonitrile (PAN), phenolic resin fiber, and viscose

*Corresponding author e-mail: mfmnasr@yahoo.com 


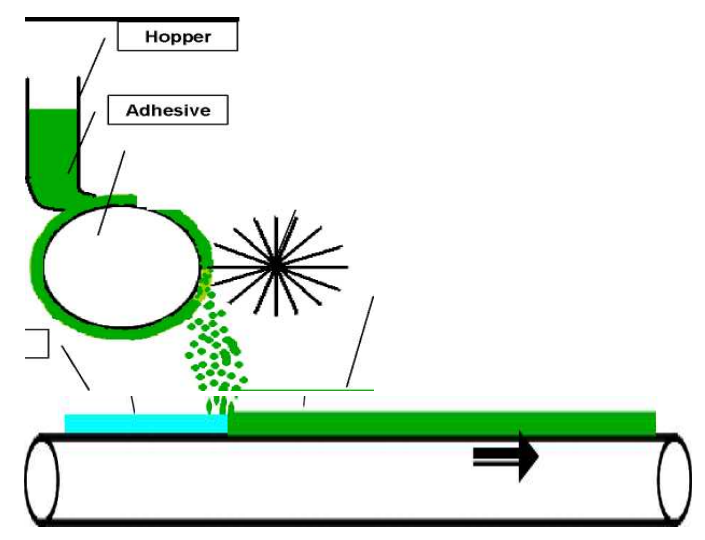

Fig. 1. Schematic diagram of production method.

rayon [3-5]. ACF has been used as a novel smart adsorbent and conductive fiber materials having several advantages over the conventional forms of activated carbon, such as powders, granules, etc. Activated carbon fabric (ACF) is a microporous carbon fiber material consisting of three-dimensional network of micrographitic layers. The micrographitic edges have a considerable amount of active functional groups (such as $-\mathrm{COOH},-\mathrm{OH}$, -CO, -O-) and dangling bonds. The huge specific surface area (up to $3000 \mathrm{~m}^{2} / \mathrm{g}$ ) is another important property of ACF[6].

The physical properties of activated carbon fibers include fast adsorption/desorption rate due to high surface area, high electrical conductivity, flexibility of designing fibers in various forms like felts, paper, and nonwovens, ease of handling, abrasion resistance, and amenable to surface functionalization and also, regeneration. It is needless to mention that the cost of precursor strongly affects the cost of the production of ACF. Hence, a lot of interest has been generated in recent years among researchers to reduce the cost of precursor. Studies have been performed on preparation and characterization of ACF from the relatively less expensive textile materials such as the waste of acrylic and cotton fibers[7,8]. This work deals with some approaches to investigate the influence of structure, frequency and temperature on the electrical and dielectric properties of the prepared samples.

\section{Aim of study}

Activated carbon fibers can be added, with small percentage, to different textile materials (fabrics or non-woven) to add engineered properties to the composed fabrics as well as to enhance the electrical properties of the resulted nonwoven fabrics that will open a wide range of

Egypt. J. Chem. 61, No. 3 (2018)

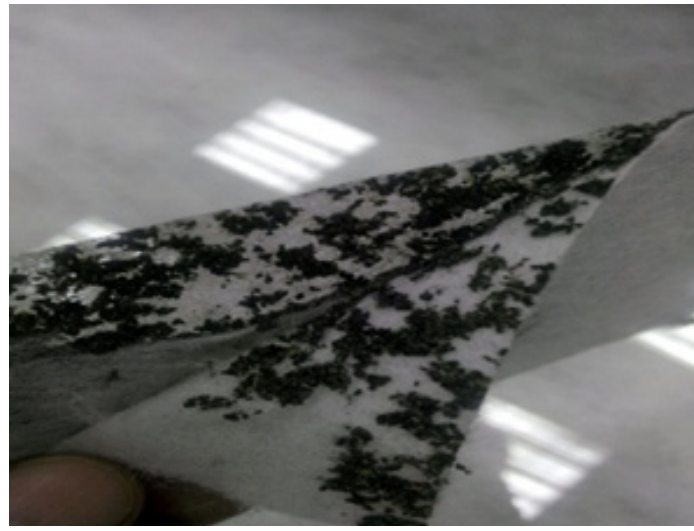

Fig. 2. Nonwoven fabric containing activated carbon

applications. It can reduce the resistance of the fabrics and remove or decrease any static charges formed of the surface of the textile fabrics. Conductive clothes can provide ideal solutions for various requirements; this mainly depends on durable material and yarn conductivity. In addition, activated carbon fibers can add a high surface area to the resulted nonwoven fabrics and garments, which can be used as a selective adsorbing filter.

\section{Experimental}

In this research different non-woven polyester fabrics produced with and without adding the activated carbons. The activated carbons used are activated carbon fiber (ACF) and carbon granules (CG).

Activated carbon fiber (ACF) is prepared from polyacrylonitrile waste fiber through carbonization at $700-1000^{\circ} \mathrm{C}$ followed by gas activation step at $900-1100^{\circ} \mathrm{C}$. Nonwoven fabrics were sewn with yarns of different materials in order to investigate the effect of stitching and number of yarn interceptions of length and width directions. The prepared nonwoven fabrics are classified into five groups as shown in the following tables:

\section{Electrical \& Dielectric Measurements}

Broadband Dielectric Spectroscopy (BDS) is employed to study the dielectric and electrical properties of the prepared samples on a broad frequency range. This is done for the three parent samples that is: Non-woven $100 \%$ activated carbon fiber (NW-ACF), Carbon Free (C-free) and Plus active carbon (PAC) at different temperatures. BDS is utilizing a high resolution Alpha analyzer with an active sample head (Novo control $\mathrm{GmbH}$ ). The complex dielectric function:

$$
\varepsilon^{*}(v)=\varepsilon^{\prime}(v)-\mathrm{i}^{\prime \prime}(v)
$$


Group 1.

\begin{tabular}{|c|c|c|c|}
\hline Sample code & $\begin{array}{l}\text { Sewing dimensions } \\
(\mathbf{m m})\end{array}$ & Type of sewing thread & Base material \\
\hline $\mathrm{C} 14$ & $50 \times 100$ & Cotton/metallic & Nonwoven without carbons \\
\hline $\mathrm{C} 8$ & $100 \times 100$ & Cotton/metallic & Nonwoven without carbons \\
\hline $\mathrm{C} 5$ & $150 \times 100$ & Cotton/metallic & Nonwoven without carbons \\
\hline $\mathrm{C} 3$ & $150 \times 150$ & Cotton/metallic & Nonwoven without carbons \\
\hline $\mathrm{C} 1$ & $150 \times 50$ & Cotton/metallic & Nonwoven without carbons \\
\hline A5 & $50 \times 50$ & Cotton/metallic & Nonwoven without carbons \\
\hline $\mathrm{CO}$ & ------ & ---------- & Nonwoven without carbons \\
\hline
\end{tabular}

Group 2.

\begin{tabular}{cccc}
\hline Sample code & $\begin{array}{c}\text { Sewing dimensions } \\
(\mathbf{m m})\end{array}$ & Type of sewing thread & Base material \\
\hline C12 & $100 \times 100$ & Teflon yarn & Nonwoven without carbons \\
C11 & $150 \times 50$ & Teflon yarn & Nonwoven without carbons \\
A14 & $100 \times 50$ & Teflon yarn & Nonwoven without carbons \\
C9 & $100 \times 150$ & Teflon yarn & Nonwoven without carbons \\
A4 & $50 \times 50$ & Teflon yarn & Nonwoven without carbons \\
C0 & -------- & Nonwoven without carbons \\
\hline
\end{tabular}

Group 3.

\begin{tabular}{cccc}
\hline Sample code & $\begin{array}{c}\text { Sewing dimensions } \\
(\mathbf{m m})\end{array}$ & Type of sewing thread & Base material \\
\hline B9 & $150 \times 50$ & polyester yarn & Nonwoven with activated carbon fiber \\
B8 & $100 \times 50$ & polyester yarn & Nonwoven with activated carbon fiber \\
B6 & $50 \times 100$ & polyester yarn & Nonwoven with activated carbon fiber \\
B2 & polyester yarn & Nonwoven with activated carbon fiber \\
B0 & $-150 \times 100$ & Nonwoven fabrics without stitches \\
\hline
\end{tabular}


Group 4.

\begin{tabular}{|c|c|c|c|c|}
\hline Sample code & Sewing dimensions & $(\mathbf{m m})$ & Type of sewing thread & Base material \\
\hline A3 & $50 \times 50$ & & polyester yarn & Nonwoven without carbons \\
\hline A 14 & $150 \times 100$ & & polyester yarn & Nonwoven without carbons \\
\hline A6 & $50 \times 150$ & & polyester yarn & Nonwoven without carbons \\
\hline A9 & $150 \times 50$ & & polyester yarn & Nonwoven without carbons \\
\hline A8 & $150 \times 150$ & & polyester yarn & Nonwoven without carbons \\
\hline $\mathrm{CO}$ & ------ & & ------ & Nonwoven without carbons \\
\hline
\end{tabular}

Group 5.

Sample code $\quad$ Sewing dimensions $(\mathrm{mm}) \quad$ Type of sewing thread $\quad$ Base material

\begin{tabular}{crrr}
\hline B4 & $50 \times 50$ & Cotton/metallic & Nonwoven with carbon granules \\
B7 & $100 \times 150$ & Cotton/metallic & Nonwoven with carbon granules \\
B6 & $50 \times 150$ & Cotton/metallic & Nonwoven with carbon granules \\
B 0 & ----- & ----- & Nonwoven fabrics without stitches \\
\hline
\end{tabular}

where, $\varepsilon^{\prime}$ - real part, $\varepsilon^{\prime \prime}-$ loss or imaginary part, i $=\sqrt{ }-1, \mathrm{n}$ - frequency) was obtained in the frequency range from $10^{-1}-10^{7} \mathrm{~Hz}$. This is equivalent to the complex conductivity function:

$$
\sigma^{*}(v)=\left(\sigma^{\prime}+\mathrm{i} \sigma^{\prime \prime}\right)
$$

That can be given from $\sigma^{*}(\omega, \mathrm{T})=\mathrm{i} \varepsilon_{0} \omega \varepsilon^{*}(\omega, \mathrm{T})$, implying that $\sigma^{\prime}=\varepsilon_{0} \omega \varepsilon^{\prime \prime}$ and $\sigma^{\prime \prime}=\varepsilon_{0} \omega \varepsilon^{\prime}\left(\varepsilon_{0}\right.$ being the vacuum permittivity). The samples were pressed between two gold-plated brass electrodes of $20 \mathrm{~mm}$ in diameter in parallel plate geometry. All measurements were carried out at room temperature except the measurements of the three parent samples were done at different temperatures ranging from $\left(-50^{\circ} \mathrm{C}\right)$ up to $\left(100^{\circ} \mathrm{C}\right)$ isothermally. The temperature was controlled by a Quatro Novocontrol cryo-system with a stability of $0.1 \mathrm{~K}$ [9-13].

\section{Results and Discussion}

Dielectric and Electrical investigations

Dielectric properties were firstly investigated for the three parent samples: $100 \%$ nonwoven free

Egypt. J. Chem. 61, No. 3 (2018) of activated carbon fiber (C-free), plus activated carbon fiber (PAC) and Non-woven 100\% activated carbon fiber (NW-ACF). The dielectric properties were measured on the considered frequency range and at different temperatures ranging from $\left(-50^{\circ} \mathrm{C}\right)$ up to $\left(100^{\circ} \mathrm{C}\right)$. Currently, we are concentrated on the conductivity of the samples. The conductivity of the three samples as a function of frequency, at relatively lower temperature $-40^{\circ} \mathrm{C}$ in comparison with that at relatively higher temperature $+90^{\circ} \mathrm{C}$, is illustrated graphically in Fig. 3. The figure shows that both the NW-ACF and the PAC samples behave as conductive materials that are not affected by the frequency. The plateau shown here represents the DC-conductivity of the material. The effect of temperature in increasing the conductivity is higher in case of PAC rather than in case of NWACF sample. This may reflect the increase of the free charge density with heating which is more convenience in PAC however it is at the level of saturation in case of NW-ACF sample. On the other hand, C-free sample shows, more or less, linear decrease of conductivity with the decrease 
in the frequency (at least down to $100 \mathrm{~Hz}$ ). This is well known behavior for all perfect insulators. The coincidence at the two considered temperatures down to $100 \mathrm{~Hz}$ is because there are no free charges that could be increased with increasing temperature. The deviation from linearity and so from coincidence at lower frequencies is due to the buildup of the dc- conductivity plateau.

Figure 4 shows the effect of temperature on the conductivity at a spot point frequency $1 \mathrm{kHz}$ for the three parent samples. The high difference between the conductivity of the three samples is clearly shown here. One has to notice that the conductivity of the NW-ACF is five orders of magnitudes higher than that when loaded on the woven and nine orders higher than that of the C-free. The effect of temperature on the conductivity of the three samples as shown in the figure is somewhat very slightly. The conductivity of the C-free sample seems to be more or less stable with a slight bend at about $40^{\circ} \mathrm{C}$. The NWACF sample shows a very slight linear increase with increasing temperature. The change of the trend from stability to linear increase for the sample PAC is shown at $40^{\circ} \mathrm{C}$ once again. Due to the huge range of conductivity values of the three different materials ranging from perfect insulator up to high conductor (about 15 decades), it is difficult to clarify the effect of temperature on the conductivity. So, one has to rescale the y axis for the three samples individually as shown in Fig. 5.

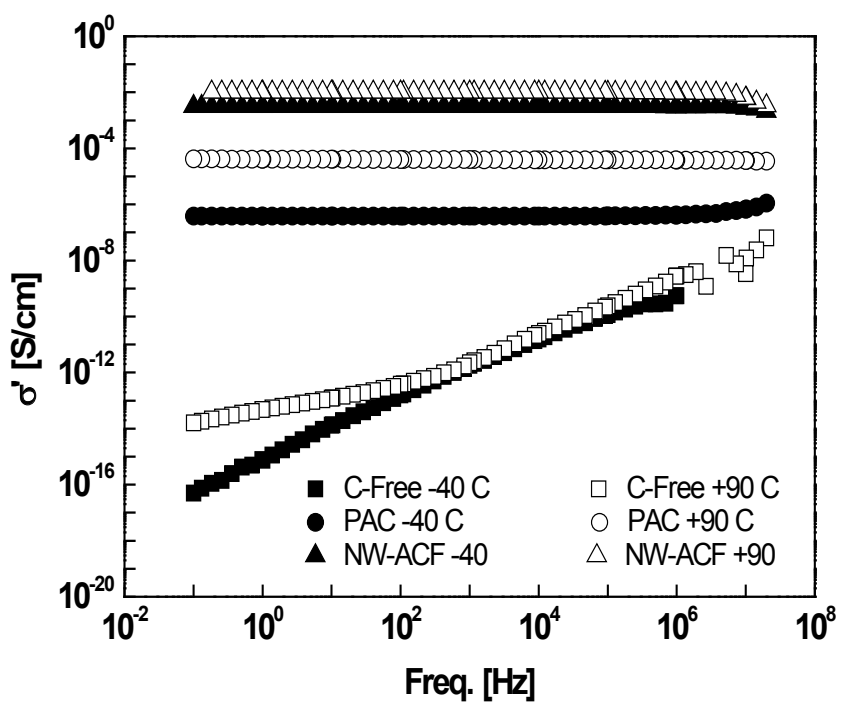

Fig. 3. The frequency dependence of conductivity for the three parent samples at two temperatures namely $-40{ }^{\circ} \mathrm{C}$ (open symbols) and $90^{\circ} \mathrm{C}$ (closed symbols).

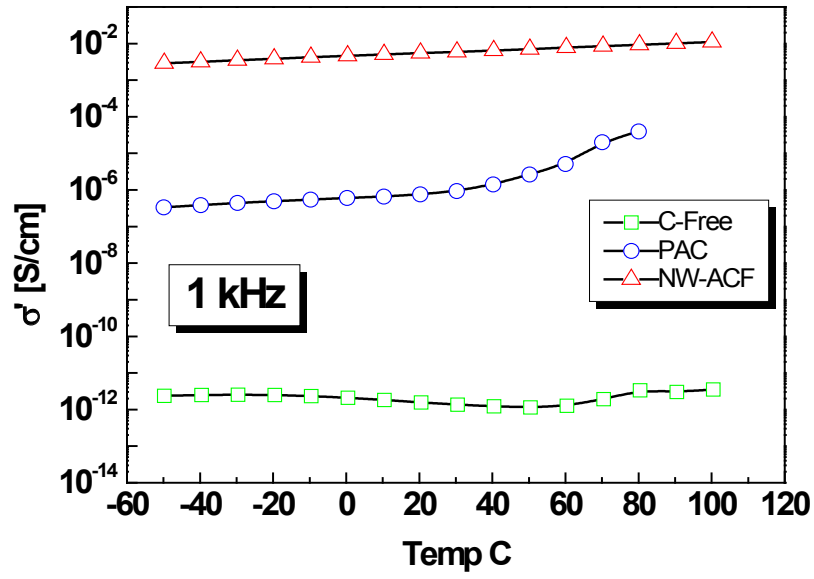

Fig. 4. The temperature dependence of conductivity for the three parent samples at spot point frequency $1 \mathrm{kHz}$. 
Rescaling of the graphically illustrated values of conductivity, in semi log illustration, shows a very clear effect of temperature that depends on the considered material. NW-ACF sample shows, in addition to its general higher values, a linear increase of conductivity with increasing temperature over the considered range of temperature.

The conductivity follows the well-known Arrhenius relation assuming that dynamics are dominated by barriers to be overcome by thermal fluctuations $[14,15]$. This implying that: $\sigma \propto \exp \left(\frac{\Delta E_{A}}{\mathbf{K}_{B} \mathbf{T}}\right)$.

where $\mathrm{k}_{\mathrm{B}}$ is Boltzmann constant and $\Delta \mathrm{E}$ activation energy. It is observed that for the $\mathrm{C}$-free sample, there is a non-Arrhenius behavior and the activation energy is temperature dependent and has many trends. However, for the PAC-sample, the conductivity follows Arrhenius in two different rates of change (from 0.005 at lower temperatures to 0.034 at higher temperatures. This indicates that the activation energy increased by about 7 times of magnitude starting from $30^{\circ} \mathrm{C}$, which is mainly due to the addition of activated carbon fiber. This temperature is close to the inflection point in case of C-free sample. The activation energy indicates an energy barrier that the ion has to overcome for a successful jump between the sites [16].

\section{Conduction Processes in Disordered Materials}

Since activated carbon fibers belong to the class of disordered materials, it is necessary that we consider the conduction process in disordered materials. Disordered states can be introduced in the material structure by a random arrangement of the atoms or by the presence of specific defects such as vacancies, dangling bonds, or chain ends. When the defect concentration becomes very high, the mean free path due to defect scattering becomes comparable to the interatomic dimensions. In this case, the concept of a free electron being scattered by defects becomes inappropriate. Instead, the concept of a localized carrier is used, which is transport via a thermallyassisted hopping or tunneling process $[17,18]$.

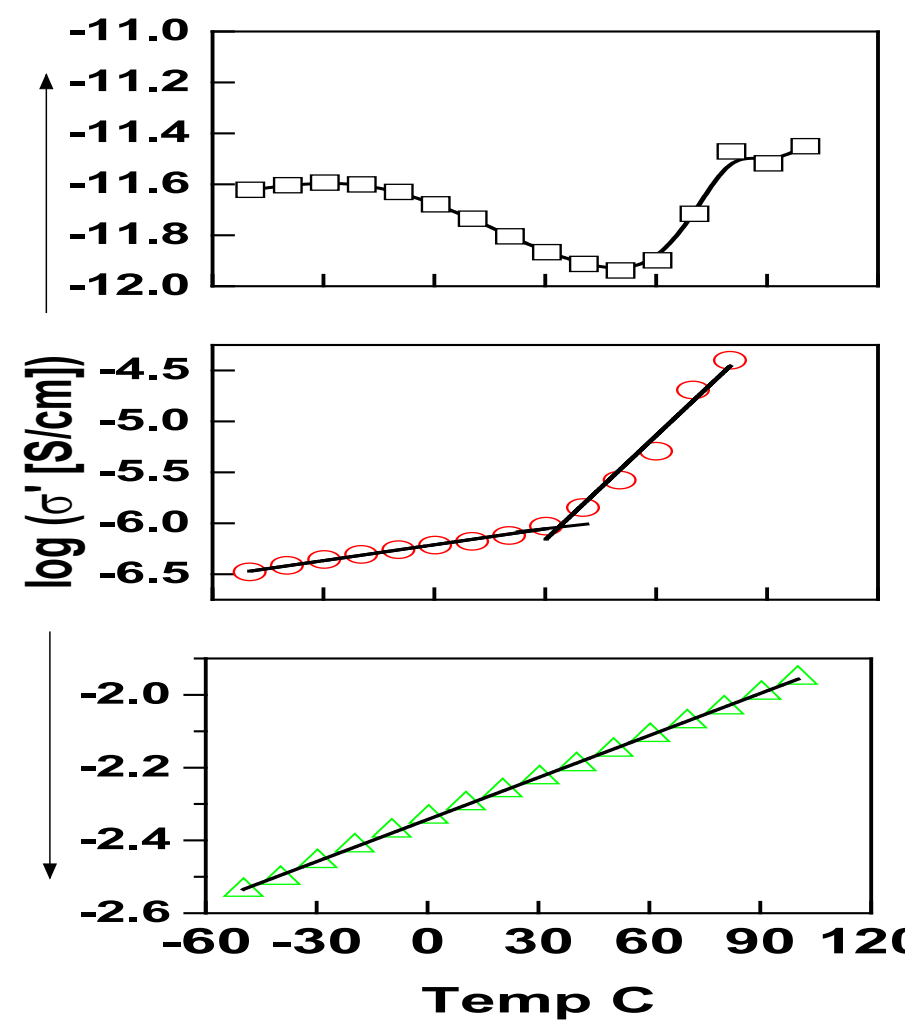

Fig. 5. The individual rescaling of the temperature dependence of conductivity for the three parent samples at spot point frequency $1 \mathrm{kHz}$.C-Free (black square), PAC (red circle) and NW-ACF (green rectangle). 
Disorder in a lattice affects both the energetic and spatial distribution of electronic states. For a random distribution of atoms, the density of electronic states tails into what is normally the forbidden zone and the electrons in these tails become localized. So in this case, there will be a mobility gap instead of energy gap. Conduction via localized electrons, which is the main conduction mechanism in ACF, implies a discrete jump across an energy barrier from one site to the next. An electron may either hop over, or tunnel through, the top of the barrier [19,20].

Further electrical investigations have been carried out at room temperature on some different textile materials with and without activated carbon fibers. We will consider here group 1 as a representative example. The first group (Group 1) basically composed of nonwoven without carbons but with a sewing thread cotton / metallic at different dimensions as given in Table 1. Figure 6 depicts the conductivity, $\sigma^{\prime}$, and dielectric loss, $\varepsilon "$ ", as a function of frequency for all the synthesized samples of group1 at room temperature.

Figure 6 shows that all the samples in the group are generally high insulators. Sample $\mathrm{C}_{0}$ (without any sewing thread) has the lowest conductivity all over the frequency range and tends to be in the order of sub Femto-Semen/cm at $0.1 \mathrm{~Hz}$. The sample C14 that of sewing dimensions 50 $\mathrm{x} 100 \mathrm{~mm}$ has the highest conductivity values (about $6 \times 10^{-12} \mathrm{~S} / \mathrm{cm}$ ). In other words, the conductivity of the group 1 varies over three decades of magnitude according to the structure of the sample. The dielectric loss shows some broad dynamic peak overlaid by a conductivity contribution at lower frequencies. The peak is gradually vanished with sewing thread cotton / metallic at different dimensions due to the effect of charge transportation. This dynamic peak could be due to the fluctuation of some terminal group such as $-\mathrm{OH},-\mathrm{COOH}$, etc.

The complex conductivity $\sigma^{*}$ is related to the complex dielectric function $\varepsilon^{*}$ according to the relationship

$$
\sigma^{*}=i 2 \pi \mathrm{f}_{0} \varepsilon^{*}
$$

with $\sigma^{*}(\mathrm{f})=\sigma^{\prime}(\mathrm{f})+\mathrm{i} \sigma^{\prime \prime}(\mathrm{f})$ resulting in

$$
\sigma^{\prime}=2 \pi \varepsilon_{\varepsilon_{0}} \varepsilon^{\prime \prime} \text { and } \sigma^{\prime \prime}=2 \pi \varepsilon_{\varepsilon_{0}} \varepsilon^{\prime}-
$$

( $\varepsilon_{0}$ is the vacuum permittivity and $f$ the frequency). The measured (total) dielectric loss, $\varepsilon_{T}$, is two parts one due to dynamic relaxation and the other is due to conductivity as given by:

$$
\varepsilon_{T}^{\prime \prime}=\varepsilon_{D}^{\prime \prime}+\varepsilon_{C}^{\prime \prime}=
$$

where $\varepsilon_{D}^{\prime \prime}$, Dynamic and, $\varepsilon_{D}^{\prime \prime}$,

Using the empirical Havriliak - Negami (HN-equation)[4], one can extract quantitative

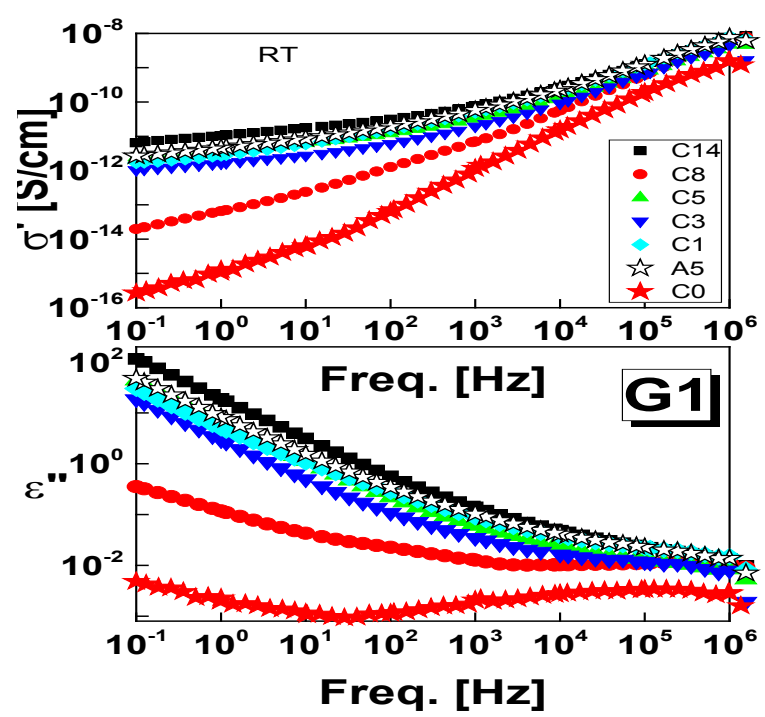

Fig. 6. The frequency dependence of conductivity and dielectric loss at room temperature (RT) for the samples of group 1. 
information regarding the dynamic relaxation and charge transportation. $\mathrm{HN}$ - function reads:

$\varepsilon_{N}^{*}(v)=\varepsilon_{\infty}+\frac{\varepsilon_{S}-\varepsilon_{\infty}}{\left(1+\left(i \frac{f}{f_{o}}\right)^{\beta_{x}}\right)^{\gamma_{N}}}+i \frac{\sigma}{2 \pi f \varepsilon_{o}}--------(6)$

The first term in equation (5) characterizes the dynamic peak relaxation with $\varepsilon_{\infty}$ the unrelaxed permittivity and $\varepsilon_{\mathrm{S}}$ is the relaxed permittivity. The difference between them is the strength of the relaxation which is proportional to the mean squared effective dipole moment and the number of fluctuating dipoles per unit volume, $\beta_{\mathrm{HN}}$ and $\gamma_{\mathrm{HN}}$ are the shape and skewness of the Cole-Cole Plot and $\mathrm{f}_{\mathrm{o}}$ is a characteristic frequency related to the frequency of maximal loss $v_{p}$ (relaxation rate) of the relaxation process under consideration. The second term is the contributions to the loss signal due to ionic conductivity were taken into account by adding the term on the right, with $\varepsilon_{0}$ being the vacuum permittivity. Figure 7 shows the permittivity, $\varepsilon^{\prime}$ and dielectric loss, $\varepsilon^{\prime \prime}$ against frequency of group 3 at room temperature.

The linear behavior on the log-log scale assures that the response here is only due to charge transportation (conductivity contribution) as explained previously by equation (2). It screened out any indication of molecular dynamic. The higher dielectric loss values and hence the conductivity values (according to the second term of equation 5) of the nonwoven fabrics without stitches, is expected in comparison with the other fabrics of the group. On the other hand, the dielectric trends accompanied by similar ones in permittivity behavior since both parameters are not independent. More inspection of the figure leads to the conclusion that there is no remarkable effect of the stitches dimensions on the dielectric loss and hence on the conductivity of the samples.

\section{Conclusion}

The dielectric and electrical properties of five different groups of non-woven polyester fabrics were investigated in the frequency range $0.1 \mathrm{~Hz}$ up to $10 \mathrm{MHz}$. In addition, the effect of temperature on the dielectric parameters of three parent samples is studied. The samples were prepared with and without adding the activated carbons [activated carbon fiber (ACF) and carbon granules (CG)], following are the main conclusions of the present study:

1. The conductivity of the NW-ACF sample is higher than that of the $\mathrm{C}$-free one by about ten orders of magnitude, which is the difference between highly conductive and highly insulator. This is simply because the electrical conductivity of ACF which is considered as a conductive material. The conduction mechanism in ACF is through the hopping or

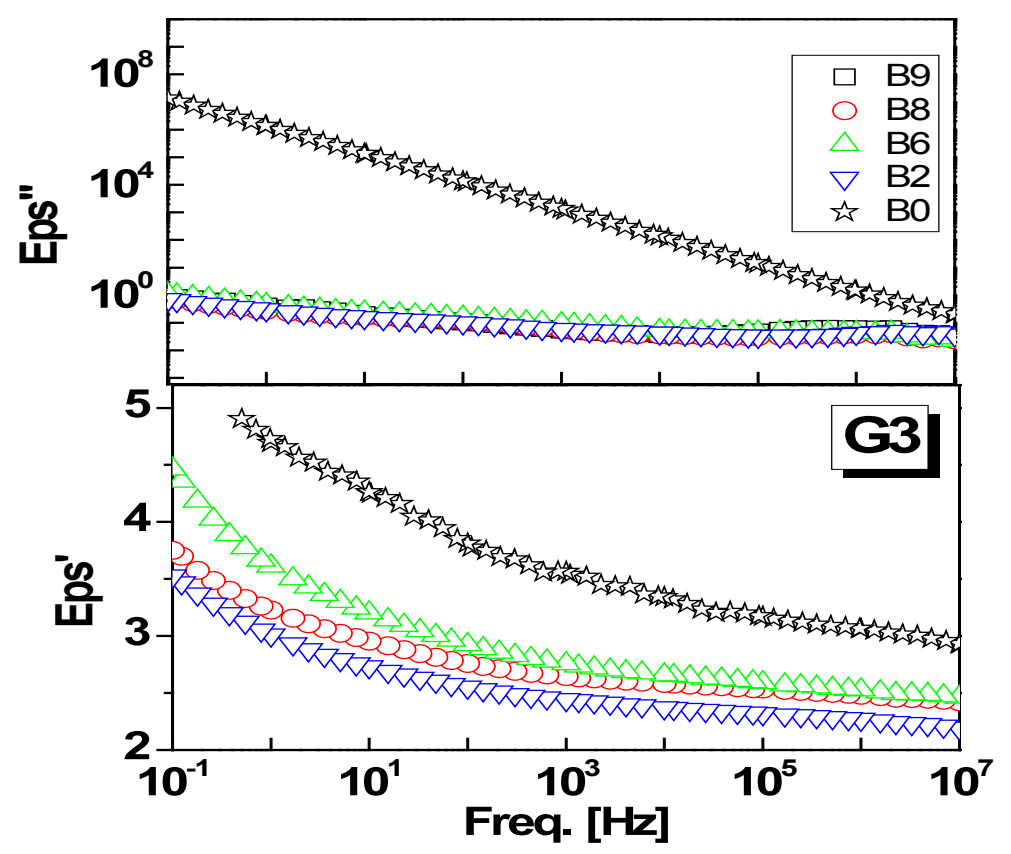

Fig. 7. The frequency dependence of conductivity and dielectric loss at room temperature (RT) for the samples of group 3.

Egypt. J. Chem. 61, No. 3 (2018) 
tunneling mechanism.

2. The conductivity increases linearly with increasing temperature over the considered range of temperature. The mechanism of the storage of the charge carriers is given by two different capacities. The first one is the capacity of the electric double layer at the interface between the electrode and the dielectric material. The second is the capacity due to the redox or what is called pseudo capacity. These results show that the produced non-woven activated carbon fiber NW-ACF can be used as smart fabric in the energy storage devices.

3. Yarn stitching and number of interceptions in length and width direction showed no influence on the measured conductivity of different samples' groups for their conductivity is basically very low.

4. Carbon Granules do not enhance the electrical and dielectric properties of the prepared nonwoven samples compared to Activated Carbon Fiber that is simply due to its weak electrical conductivity.

Further work should be done in order to optimize the electrical conductivity that could be applied in the field of energy storage devices.

\section{References}

1- Malkan R., and Larry C.W., A review on spunbond technology, Part I. Nonwovens, 3, 4-14 (1992).

2- http://www.academia.edu/440297/Comparison_ of_web_formation_and_bonding_methods.

3- Suzuki M., Activated carbon fiber: fundamental and applications, Carbon, 32 (2), 577-586 (1994).

4- Ehrburger P., Pusset N., and Dziedzinl P., Active surface area of microporouscarbons. Carbon, 30 (7), 1105-1109 (1992).

5- Smisek M., and Cerny S., Active Carbon Manufacture, Properties and Applications, ElsevierPublishing Company, New York, (1970).

6- Ko T.-H., Influence of continuous stabilization on the physical properties and microstructureof PANbased carbon fibers, J. Appl. Polym. Sci., 42 (7), 1949-1957 (1991).

7- Ryu S-K., Porosity of Activated Carbon Fiber, High Temperature-High Pressures 22, 345-351 (1990).

8- Bashir Z., A Critical Review of The Stabilization of Polyacrylonitrile, Carbon, 29, 1081-1088 (1991).

9- El-Sabbagh S. H., Ahmed N. M., Turky G. M.,
Selim M. M. “Chapter 8: Rubber nano-composites with new core-shell metal oxides as nano-fillers" in [Progress in Rubber Nanocomposites], A volume in Woodhead Publishing Series in Composites Science and Engineering, 249-283 (2017).

10- Kremer F., and Schönhals A., Broadband Dielectric Spectroscopy, Springer, (2003).

11- Turky G., Shaaban Sh. S., and Schönhals A., Broadband dielectric spectroscopy on the molecular dynamics in different generations of hyperbranched polyester, J. Appl. Polym. Sci, 113, 2477-2484 (2009).

12- Saad M. A., El-Newashy R. F. and Turky G. M., Stitch Designed Intelligent Clothing Based on Warp Knitted Fabric, The 7th International Conference of Textile Research Division NRC, Cairo, Egypt Oct. 10-12 (2010).

13- El-Newashy R. F., Saad M.A. and Turky G. M, Integration of Conductive Yarns into Fabric by Stitching, Journal of American Science, 8 (3), 213-217 (2012).

14- Suthanthiraraj S. A., Sheeba D. J. and Paul B. J., Impact of ethylene carbonate on ion transport characteristics of $\mathrm{PVdF}-\mathrm{AgCF}_{3} \mathrm{SO}_{3}$ polymer electrolyte system, Mater. Res. Bull,44, 15341539 (2009).

15- Shujahadeen B.A., Ranjdar M. A., Mariwan A. and Hameed M. A., Role of Ion Dissociation on DC Conductivity and Silver Nanoparticle Formation in PVA:AgNt Based Polymer Electrolytes: Deep Insights to Ion Transport Mechanism, Polymers, 9, 338-345 (2017).

16- Logan S.R., The origin and status of the Arrhenius equation, J. Chem. Educ., 59 (4), 279-307 (1982).

17- Blythe A.R., Electrical Properties of Polymers. Cambridge University Press, London. New York. Melbourne (1979).

18- Marchand A., Electronic Properties of Doped Carbons, Chemistry and Physics of Carbon,7, 155 (1975).

19- Fung A., Dressel haus M. S., and Endo M., Transport Properties Near the Metal-insulator Transition in Heat-treated Activated carbon Fibers, Phys. Rev. B, 48, 14953 (1993).

20- Vittorio S.L., Dresselhaus M.S., Endo M., The Transport properties of Activated Carbon Fibers, J. Mater. Res., 6, 778-783 (1991).

(Received 25/3/2018; accepted 6/5/2018) 


\section{الخصائص الكهربائية والعازلة للأقمشة الغيرمنسوجة والمصممة هندباوالتي تحتوي على ألياف الكربون النشطة

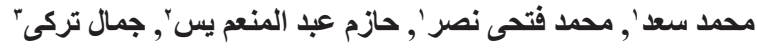

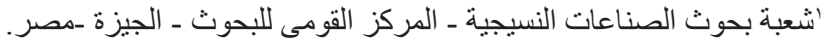

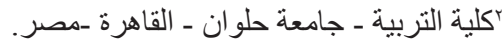

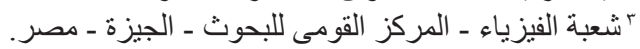

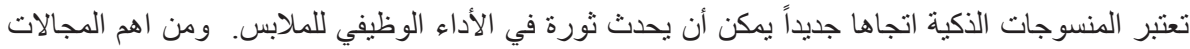

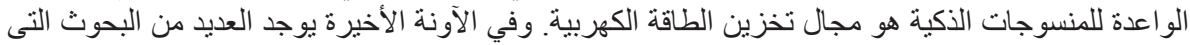

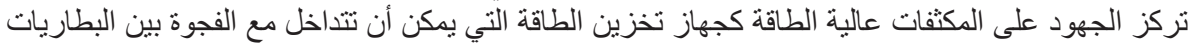
و المكثفات التقليدية.

ألياف الكربون النشطة واحدة من اهم المو اد الملائمة لهذا التطبيق. وتم إعداد مجمو عات مختلفة من البوليستر

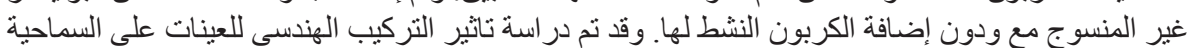

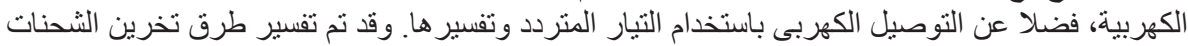

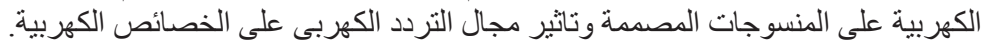

وقد وجد ان الاقمشة الغير منسوجة والمحضرة باضافة الياف الكربون النشطة لها افضل النتائج من بين

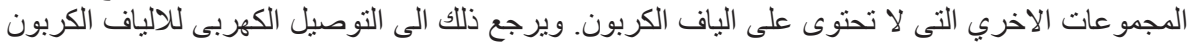

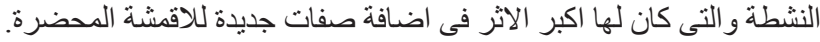

